\title{
Relationships between Dietary Intake and Body Composition according to Gross Motor Functional Ability in Preschool-Aged Children with Cerebral Palsy
}

\author{
Jacqueline L. Walker ${ }^{a, b}$ Kristie L. Bell ${ }^{a-d}$ Richard D. Stevenson ${ }^{f}$ Kelly A. Weir ${ }^{b, e}$ \\ Roslyn N. Boyd ${ }^{\text {b-d }}$ Peter S.W. Davies ${ }^{a}$ \\ ${ }^{a}$ Children's Nutrition Research Centre and ${ }^{b}$ Queensland Cerebral Palsy and Rehabilitation Research Centre, School of \\ Medicine, 'Queensland Children's Medical Research Institute, University of Queensland, and dDepartment of Paediatric

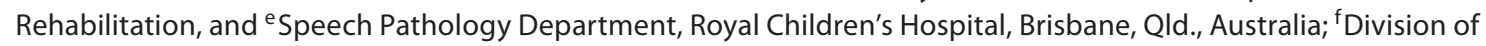 \\ Developmental Pediatrics, Department of Pediatrics, University of Virginia, School of Medicine, Charlottesville, Va., USA
}

\section{Key Words}

Body composition - Cerebral palsy · Children - Dietary

intake $\cdot$ Functional ability $\cdot$ Preschool-aged children

\begin{abstract}
Background/Aims: We aimed to determine the relationships between energy intake, macronutrient intake and body composition in preschool-aged children with cerebral palsy (CP) according to gross motor functional ability in comparison with typically developing children (TDC). Methods: Seventy-three children with CP (70\% male) of all functional abilities and 16 TDC (63\% male) aged $2.8 \pm 0.9$ years participated in this study. Dietary intake was measured via a validated 3-day weighed food record. Body composition was determined via isotope dilution techniques. Results: There was a significant relationship between energy intake and fatfree mass index, which was stronger in TDC compared to children with CP. There were no significant correlations between other dietary intake and body composition variables, despite differences in body composition as ambulatory status declined. Non-ambulant, tube-fed children had significantly lower protein intakes compared to orally fed children. No other differences in macronutrient intake between chil-
\end{abstract}

dren with CP and TDC were apparent. Conclusions: Results suggest that relationships between dietary intake and body composition are not evident in this population, but develop over time. Physical activity levels may have a greater impact on body composition at this age. Longitudinal research is required to examine these factors.

Copyright $\odot 2012$ S. Karger AG, Basel

\section{Introduction}

Growth in the majority of children with cerebral palsy (CP) remains atypical [1-3], despite continued research interest. Nutritional concerns are evident regardless of a child's gross motor functional ability level, motor type or distribution [4-8], and have the potential to persist into adulthood [9]. Altered body composition (namely decreases in fat-free mass (FFM), and differing levels of body fat) [6, 10-16] and inadequate dietary intake [17-19] have been detailed in children with CP. These nutritional factors may help explain the aetiology of atypical growth and development in this population $[5,7,8]$; however, the links between them are not well established.

\section{KARGER}

Fax +4161306 1234

E-Mail karger@karger.ch

www.karger.com
(C) 2012 S. Karger AG, Basel

0250-6807/12/0614-0349\$38.00/0

Accessible online at:

www.karger.com/anm
Jacqueline L. Walker

Children's Nutrition Research Centre, Department of Paediatrics and Child Health University of Queensland, Level 3, Foundation Building, Royal Children's Hospital Herston Road, Herston, QLD 4029 (Australia)

E-Mail j.walker3@uq.edu.au 
Previous literature has shown that nutritional rehabilitation can alter body composition in children with severe CP $[15,19]$. Studies have focused on the effects of gastrostomy feeding, and have reported significant increases in various body composition parameters $[10,15$, 20]. For example, in 21 non-ambulant children with severe $\mathrm{CP}$ aged between 4-18 years, the introduction of gastrostomy feeding was shown to significantly increase total body protein and body fat over a median time frame of 20.6 months [15]. Unfortunately, there was no ability to associate these outcomes to increases in specific nutrients as dietary intake was not measured. Sullivan et al. [19] investigated the effect of 12 months of gastrostomy tube feeding on the body compositions of 57 children aged between 5 months and 17 years, $95 \%$ of whom were not ambulatory. Findings of significant increases in subcutaneous fat deposition were associated with increased energy intake, which was predominately associated with increased fat intake. Body composition measures, however, were not via a gold standard.

A recent study showed that targeted nutritional rehabilitation has the potential to alter body composition favourably [20]. Excessive deposition of body fat was avoided by using a low-energy, micronutrient-complete enteral feed. Follow-up data for 5 children indicated significantly increased linear growth and weight gain with no disproportionate change in body fat storage [20]. Whether these outcomes were due to changes in dietary fat intake, protein intake or overall energy intake remains unclear and requires further investigation. Published literature currently only concerns those non-ambulant children with severe CP.

Knowledge of the relationships between dietary intake and body composition in preschool-aged children with $\mathrm{CP}$ of a range of functional abilities is extremely important to guide further studies regarding nutritional rehabilitation in children with $\mathrm{CP}$ of all ages in addition to clinical practice. The aim of this study was to determine the relationships between energy intake, macronutrient intake and body composition via a gold standard measure in preschool-aged children with CP according to gross motor functional ability in comparison to typically developing children (TDC).

\section{Subjects and Methods}

\section{Participants}

All children with CP were recruited from two prospective, longitudinal, representative cohort studies, which were funded by the National Health and Medical Research Council
(NHMRC) of Australia: the Queensland CP Child Study of Motor Function and Brain Development (NHMRC 465128, n = 240) and the Queensland CP Child Study: Growth, Nutrition and Physical Activity (NHMRC 569605, $\mathrm{n}=240$ ), being conducted by the Children's Nutrition Research Centre (CNRC) and the Queensland Cerebral Palsy Research and Rehabilitation Centre. Eligible children were required to have a confirmed diagnosis of CP by a neurologist or developmental paediatrician [21], be aged between 1.4 and 5.1 years at the time of assessment, and residing in Queensland, Australia. Children with a progressive or neurodegenerative lesion, or a genetic abnormality known to impact on growth or body composition were excluded. Recruitment for TDC was via advertisements through the University of Queensland, CNRC website, and word of mouth. Typically developing siblings of the children with $\mathrm{CP}$ were also invited to participate. Children were eligible if they were living in Queensland, Australia, were in the same age range, and had no condition or were taking no medications that altered body composition. This was confirmed on screening with parents at study entry. Children with CP or TDC who were under- or overweight were not excluded from this study in order to obtain a representative sample. Parents or legal guardians gave written, informed consent on behalf of the participants. Appointments were conducted at the closest tertiary centre or at one of nine outreach locations for all children. The same study team collected data at all geographic locations. Corrected age was calculated for children under 2 years of age who were born at less than 37 weeks gestation. Chronological age was used for all other children.

\section{Anthropometry}

All measurements were taken by one of three trained dietitians. Body weight was measured to the nearest $100 \mathrm{~g}$ using portable electronic scales (Homemaker Ltd, Australia) or chair scales (Seca Ltd, Germany). A portable length measuring board (Shorr Productions, USA) was used to measure height or length (for children under 2 years of age or those unable to stand correctly) to the last completed millimetre. In children where an accurate measure of height or length was not possible, knee height was measured with an anthropometer (Holtain Ltd, UK) to the last completed millimetre. Knee height was then used to predict height using published equations developed previously from a population of children with CP [7].

\section{Dietary Intake}

A 3-day, weighed food record was completed for each child by parents or carers, detailing all food and fluids consumed over 2 weekdays and 1 weekend day [22]. Families were provided with the necessary equipment, including kitchen scales accurate to $0.1 \mathrm{~g}$ and a paper-based 3-day food record [23]. The record was adapted by a dietitian specifically for the study, and parents were asked to record foods and fluids offered as well as leftovers and spills to obtain specific amounts actually consumed by their child. Parents were encouraged to include the brand names of foods and fluids, any recipes used, and provide details on cooking method. One research dietitian coded and analysed all food records using the Foodworks ${ }^{\mathrm{TM}}$ dietary analysis software (2009; Xyris Software, Australia). Before analysis, inconsistencies in records were checked extensively with parents via telephone. Mean energy intake calculations $(\mathrm{kJ} /$ day) for each child were weighted according to the days recorded. The 2 weekdays had a significant- 
ly greater impact upon the mean energy intake value when compared to the 1 weekend day, as they represent 5/7 of a weekly energy intake value. This modified 3-day weighed food record has been shown to accurately measure energy intake in a subset of this cohort of children. In a sample of 31 children aged $3.7 \pm 0.5$ years of all gross motor functional abilities and motor types, the bias in energy intake measured via the record as a percentage of total energy expenditure measured by the doubly labelled water method was lower than 15\% [62]. This is less than published data detailing typical within-subject variability in day-to-day energy intake [24]. Energy intake data were expressed as kilojoules per kilogram FFM per day. The power to which FFM was raised to adequately adjust for body composition and body weight was determined by the log-log regression of energy intake and FFM [25]. This was done separately for the children with $\mathrm{CP}$ and the TDC due to known differences in the relationship between total energy expenditure and FFM [16].

\section{Body Composition}

Isotope dilution procedures were used to non-invasively measure body composition. The deuterium dilution technique [26] was used for the majority of children (59 children with CP) and oxygen-18 was used for 14 children with CP and all 16 TDC [27]. This was due to a small subset of the children being involved in a concurrent study investigating total energy expenditure via the doubly labelled water method. The dilution space for oxygen-18 was used to determine body composition for these children instead of deuterium due to greater accuracy $[28,29]$. Children were given a dose of deuterium or oxygen-18 in the form of water, either orally or via a feeding tube. Prior to dosing, a single urine sample was collected from each child to determine natural baseline enrichments of the isotopes in the body. For the deuterium dilution technique, a second urine sample was collected approximately $5 \mathrm{~h}$ after dosing [26]. If the child was dosed with oxygen-18, daily samples were collected for the 10 days following the appointment [27]. A Dual Inlet Isoprime isotope ratio mass spectrometer (Isoprime Dual Inlet IMRS; IonVantage Software, Isoprime, UK) was used to analyse urine samples to determine isotopic enrichments. Standard equations [26] were used to calculate dilution spaces for both deuterium and oxygen-18, which were then adjusted by 4 and 1\%, respectively, to correct for overestimation when compared to the body water pool $[28,29]$. The accuracy, therefore, of the techniques to determine total body water is excellent at approximately $4 \%$ for deuterium and $1 \%$ for oxygen- 18 [28, 29], with a minimal difference between the methods. Resulting total body water values were then divided by age- and genderspecific hydration factors to give a result for FFM [30]. To account for the influence of height, FFM was adjusted to give an FFM index (FFMI; FFM/height ${ }^{2}$ ) [31]. Body fat was determined by subtracting the FFM value from the total body weight of the subject and converted to body fat percentage to account for weight differences between children [32].

\section{Gross Motor Functional Ability}

The gross motor functional ability for the children with $\mathrm{CP}$ was determined using a validated classification known as the Gross Motor Function Classification System (GMFCS) [33, 34]. This system classifies children into one of five functional levels (I-V). To enable meaningful analyses in the current study, the five levels were condensed into two groups to describe outcomes based on walking ability: children who are ambulant (GMFCS I and II - mild CP) and children who are marginally ambulant or nonambulant (GMFCS III, IV and V - moderate-to-severe CP).

\section{Feeding Difficulties}

The oral motor and swallowing dysfunction (oropharyngeal dysphagia) of all children was objectively measured by a speech pathologist using the Feeding and Swallowing Competency Subset (Part 2) of the Dysphagia Disorders Survey - Pediatric [35], a reliable, valid tool [36]. Children were classified into four groups - no feeding difficulties, mild feeding difficulties, moderate-to-severe feeding difficulties and profound (non-oral) feeding difficulties. This outcome measure was considered as a confounding variable in the statistical analyses of dietary data.

\section{Ethics}

This study was part of a larger research project investigating the growth, nutrition and physical activity of young children with CP, which was funded by the National Health and Medical Research Council (NHMRC 569605; Australia New Zealand Clinical Trials Registry No.: ACTRN12611000616976) [23]. Ethical approvals were obtained from the Children's Health Services District Ethics Committee (HREC/08/QRCH/112/AM01 and HREC/09/QRCH/124), the University of Queensland Medical Research Ethics Committee (2008002260 and 2009001869), the Cerebral Palsy League of Queensland Ethics Committee (CPLQ2007/09-1029), the Gold Coast Health Service District Human Research Ethics Committee (HREC/09/QGC/88), the Townsville Health Service District Human Research Ethics Committee (HREC/09/QTHS/96), the Central Queensland Human Research Ethics Committee (SSA/10/QCQ/13) and the Mater Health Services Human Research Ethics Committee (1520EC).

\section{Power Calculations}

Sample size calculations were based on the number of children required to detect a biologically and clinically significant difference between two variables of interest, for example, FFMI and energy intake. A sample size of 16 children for each group would be sufficient that a correlation of 0.5 between two variables would be statistically significant with $80 \%$ power and $5 \%$ significance. This sample size was also sufficient to identify a 1-SD difference in energy intake (i.e. $1,042 \mathrm{~kJ})[22,37]$ between the two groups as being statistically significant with $80 \%$ power and $5 \%$ significance.

\section{Statistics}

Statistical analyses were performed using Statistical Package for the Social Sciences (version 20; IBM SPSS Statistics 20.0). Children with $\mathrm{CP}$ were grouped according to walking ability and the fourth group consisted of the TDC. Weight and height $z$-scores were calculated based on age and gender using the Centers for Disease Control data [38] and incorporating the LMS (least mean square) method [39]. Measures of age, weight, height and body composition between the total population of children with $\mathrm{CP}$ and TDC were compared using independent $t$ tests. Measures of age, weight and height were compared between functional ability groups and TDC using one-way analysis of variance (ANOVA) and post hoc Tukey HSD (honestly significant difference) tests to account for multiple comparisons. Measures of body composition were compared between functional ability groups and TDC using 
Table 1. Anthropometric, body composition and dietary intake measures and feeding difficulties for children with $\mathrm{CP}$ according to gross motor functional ability and $\mathrm{TDC}^{1}$

\begin{tabular}{lcccc}
\hline & $\begin{array}{l}\text { Ambulant } \\
\text { (GMFCS I/II) } \\
(\mathrm{n}=48)\end{array}$ & $\begin{array}{l}\text { Marginally ambulant/non- } \\
\text { ambulant (GMFCS III-V) } \\
(\mathrm{n}=25)\end{array}$ & $\begin{array}{l}\text { All children } \\
\text { with CP } \\
(\mathrm{n}=73)\end{array}$ & $\begin{array}{l}\text { TDC } \\
(\mathrm{n}=16)\end{array}$ \\
\hline Age, years & $2.6 \pm 0.8^{2}$ & $2.6 \pm 0.9^{2}$ & $2.6 \pm 0.8^{3}$ & $3.7 \pm 0.5$ \\
Weight z-score & $-0.1 \pm 1.0$ & $-1.0 \pm 1.8^{2,4}$ & $-0.4 \pm 1.4^{3}$ & $0.6 \pm 0.6$ \\
Height z-score & $-0.1 \pm 1.0$ & $-0.8 \pm 1.3^{2,4}$ & $-0.3 \pm 1.1^{3}$ & $0.5 \pm 0.7$ \\
FFMI, kg/m 2 & $13.1 \pm 1.5$ & $11.5 \pm 1.6^{5,6}$ & $12.6 \pm 1.7$ & $12.7 \pm 1.0$ \\
Body fat, \% & $18.6 \pm 6.4$ & $22.2 \pm 10.0$ & $19.8 \pm 7.9$ & $23.0 \pm 3.6$ \\
EI, kJ/kg FFM/day & $422 \pm 82$ & $367 \pm 73^{7}$ & $403 \pm 83$ & $397 \pm 69$ \\
Protein intake, g/kg/day & $3.1 \pm 0.7$ & $2.7 \pm 1.2$ & $2.9 \pm 0.9$ & $2.9 \pm 0.7$ \\
Protein intake, \% of EI & $15.4 \pm 3.0$ & $15.5 \pm 4.4$ & $3.4 \pm 3.5$ & $15.9 \pm 2.0$ \\
Fat intake, g/kg/day & $3.1 \pm 0.8$ & $2.7 \pm 0.9$ & $3.0 \pm 7.2$ & $31.2 \pm 8.0$ \\
Fat intake, \% of EI & $33.7 \pm 7.3$ & $34.5 \pm 7.1$ & $24(33)$ & $13(81)$ \\
Feeding difficulties, $\mathrm{n}$ (\%) & $22(46)$ & $2(8)$ & $21(29)$ & $1(6)$ \\
$\quad$ None & $17(35)$ & $4(16)$ & $26(35)$ & $2(13)$ \\
$\quad$ Mild & $9(19)$ & $17(68)$ & $2(2)$ & 0 \\
\multicolumn{1}{l}{ Moderate to severe } & 0 & $2(8)$ & &
\end{tabular}

${ }^{1}$ All values are means \pm SDs. ${ }^{2} \mathrm{p}<0.05$ vs. TDC (one-way ANOVA and post hoc Tukey HSD tests). ${ }^{3} \mathrm{p}<0.05$ vs. TDC (independent $t$ tests). ${ }^{4} \mathrm{p}<0.05$ vs. ambulant children (one-way ANOVA and post hoc Tukey HSD tests). ${ }^{5} \mathrm{p}<0.05$ vs. TDC (one-way ANCOVA correcting for age and using the Bonferroni correction for multiple comparisons). ${ }^{6} \mathrm{p}<0.001 \mathrm{vs}$. ambulant children (one-way ANCOVA correcting for age and using the Bonferroni correction for multiple comparisons). ${ }^{7} \mathrm{p}<0.01 \mathrm{vs}$. ambulant children (one-way ANCOVA correcting for age and feeding difficulties and using the Bonferroni correction for multiple comparisons). EI = Energy intake.

one-way analysis of covariance (ANCOVA) correcting for age and using the Bonferroni correction for multiple comparisons. Dietary intake measures were compared between the total population of children with CP and TDC using multiple regressions, accounting for the influence of age and feeding difficulties. Dietary intake measures were compared between functional ability groups and TDC via one-way ANCOVA, accounting for the influence of age and feeding difficulties and using the Bonferroni correction for multiple comparisons. Relationships between body composition and dietary intake variables were determined using partial correlation accounting for the influence of feeding difficulties. Differences in these relationships between groups of children were established using multiple regressions.

\section{Results}

A total of 73 children with CP (70\% male), mean age $2.6 \pm 0.8$ years (range $1.5-4.3$ years) participated in this study. A total of $58 \%$ of children were born at term ( $\mathrm{n}=$ $42)$, with the remaining $42 \%(\mathrm{n}=31)$ born preterm. Children represented all GMFCS levels $(I=39, I I=9, I I I=9$, $\mathrm{IV}=7$ and $\mathrm{V}=9$ ), and predominant motor types included spasticity $(n=60)$, dystonia $(n=2)$, athetosis $(n=3)$ and hypotonia $(\mathrm{n}=8)$. A total of 24 children $(33 \%)$ presented with no feeding problems, and 21 children (29\%) with mild feeding problems. Moderate-to-severe or profound (non-oral) feeding problems were present in 28 children (37\%), 19 of whom were classified as GMFCS III, IV or V. Six children were tube fed, all of whom were classified as GMFCS V. Epilepsy was present in 12 children (16\%). Sixteen TDC children ranging in age from 3.0 to 4.5 years (mean $3.7 \pm 0.5$ years) also participated.

Log-log regression concerning energy intake and FFM for the children with CP resulted in a value of 0.96 as the power function, with a $95 \%$ confidence interval (CI) of $0.68-1.26$. For the TDC, the power function was 0.92 , with a $95 \%$ CI of -0.11 to 1.43 . Hence, a power function of 1 was applied to express energy intake relative to FFM for all children involved in the study due to overlapping CI that included a value of 1 .

For all children, results of anthropometric data, body composition, dietary intake and feeding difficulty are displayed in table 1 . Overall, the children with $\mathrm{CP}$ were younger, (mean difference, $\mathrm{MD}=-1.1$ years, $95 \% \mathrm{CI}=$ -1.5 to -0.7 years, $\mathrm{p}<0.001)$, lighter $(\mathrm{MD}=-1.0,95 \%$ 
$\mathrm{CI}=-1.7$ to $-0.3, \mathrm{p}<0.001)$ and shorter $(\mathrm{MD}=-0.9,95 \%$ $\mathrm{CI}=-1.5$ to $-0.3, \mathrm{p}=0.004)$ compared to the TDC. There was no difference in FFMI or body fat percentage, which could be attributed to greater numbers of ambulant children compared to marginally ambulant or non-ambulant children. There was also no significant difference in energy intake between the children with CP and TDC. Considering gross motor functional ability, as expected, significant differences in body composition and energy intake were evident between the children groups. Marginally ambulant and non-ambulant children were lighter $(\mathrm{MD}=-0.9,95 \% \mathrm{CI}=-1.6$ to $-0.2, \mathrm{p}=0.011)$, shorter $(\mathrm{MD}=-0.7,95 \% \mathrm{CI}=-1.3$ to $-0.1, \mathrm{p}=0.029)$, had a lower FFMI (MD $=-1.6,95 \% \mathrm{CI}=-2.4$ to $-0.7, \mathrm{p}<0.001)$ and a lower energy intake $(\mathrm{MD}=-70 \mathrm{~kJ} / \mathrm{kg} \mathrm{FFM} /$ day, $95 \%$ $\mathrm{CI}=-125$ to $-15, \mathrm{p}<0.01)$ compared to the ambulant children. Non-ambulant children were also lighter $(\mathrm{MD}=-1.6,95 \% \mathrm{CI}=-2.4$ to $-0.8, \mathrm{p}<0.001)$, shorter $(\mathrm{MD}=-1.3,95 \% \mathrm{CI}=-2.0$ to $-0.6, \mathrm{p}<0.01)$ and had a lower FFMI (MD $=-1.5,95 \% \mathrm{CI}=-2.7$ to $-0.2, \mathrm{p}<0.05)$ compared to the TDC. Ambulant children were younger than the TDC $(\mathrm{MD}=-1.1$ years, $95 \% \mathrm{CI}=-1.6$ years to -0.6 years, $\mathrm{p}<0.001)$, but similar in all other anthropometric, body composition and dietary intake aspects. When considering the macronutrient composition of the diet, there were no significant differences between any groups of children with $\mathrm{CP}$ according to gross motor functional ability and TDC for protein intake or fat intake, whether this was in relation to body weight $(\mathrm{g} / \mathrm{kg} /$ day) or energy intake (\% of energy intake).

Marginally ambulant and non-ambulant children were further analysed to determine differences in anthropometric, body composition and dietary intake variables between children who were orally fed and those who were tube fed, as displayed in table 2 . Protein intake, both relative to body weight $(\mathrm{g} / \mathrm{kg} /$ day $)$ and relative to overall energy intake (\%), was significantly lower in the tube-fed children compared to the orally fed children $(\mathrm{MD}=-1.2 \mathrm{~g}, 95 \% \mathrm{CI}=-2.2$ to $-0.1 \mathrm{~g}, \mathrm{p}=0.037$; and $\mathrm{MD}=-4.5 \%, 95 \% \mathrm{CI}=-8.4$ to $-0.7 \%, \mathrm{p}=0.023$, respectively) despite a smaller sample size.

The relationships between body composition and dietary intake variables, when accounting for any feeding difficulties, were investigated. There was a significant correlation between energy intake and FFMI in all children with $\mathrm{CP}(\mathrm{r}=0.36, \mathrm{p}=0.002)$, which was stronger in the $\operatorname{TDC}(\mathrm{r}=0.57, \mathrm{p}=0.026)$. The relationship between energy intake and FFMI was not significantly different between these two groups of children (in terms of both the intercept and the slope of the regression line; fig. 1). In both
Table 2. Anthropometric, body composition and dietary intake measures for marginally ambulant and non-ambulant children (GMFCS III-V) with CP according to feeding method ${ }^{1}$

\begin{tabular}{lcc}
\hline & Orally fed $(\mathrm{n}=19)$ & Tube fed $(\mathrm{n}=6)$ \\
\hline Age, years & $2.6 \pm 1.0$ & $2.8 \pm 0.5$ \\
Weight $\mathrm{z}$-score & $-0.9 \pm 1.6$ & $-1.0 \pm 2.2$ \\
Height $\mathrm{z}$-score & $-0.9 \pm 1.3$ & $-0.4 \pm 1.3$ \\
FFMI, kg/m ${ }^{2}$ & $11.8 \pm 1.6$ & $10.6 \pm 1.4$ \\
Body fat, \% & $20.8 \pm 7.6$ & $26.9 \pm 15.4$ \\
EI, kJ/kg FFM/day & $376 \pm 75$ & $341 \pm 66$ \\
Protein intake, g/kg/day & $2.9 \pm 1.2$ & $1.8 \pm 0.6^{2}$ \\
Protein intake, \% of EI & $16.6 \pm 4.4$ & $12.0 \pm 2.0^{2}$ \\
Fat intake, g/kg/day & $2.7 \pm 0.8$ & $2.6 \pm 1.3$ \\
Fat intake, \% of EI & $33.5 \pm 6.1$ & $37.6 \pm 9.5$ \\
\hline
\end{tabular}

${ }^{1}$ All values are means \pm SDs. ${ }^{2} \mathrm{p}<0.05$ vs. those children who were orally fed (independent t tests). EI = Energy intake.

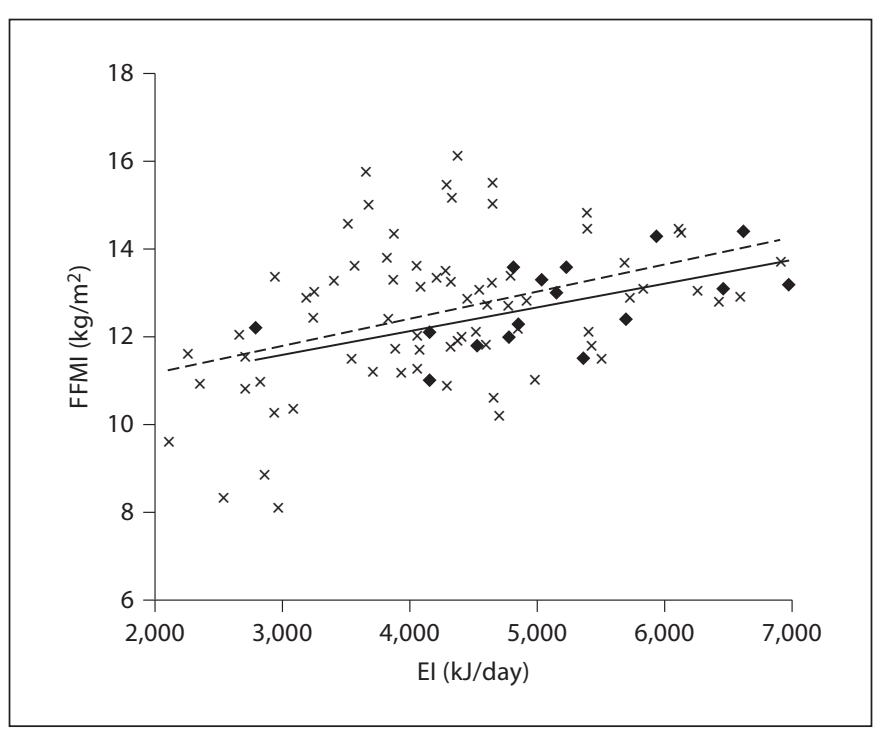

Fig. 1. Scatter plot of the relationship between energy intake (EI) and FFMI for children with CP $(\times ;---)$ and TDC $(-;-)$ determined via partial correlation accounting for the influence of feeding difficulties. CP children $(\mathrm{n}=73)$ : FFMI $\left(\mathrm{kg} / \mathrm{m}^{2}\right)=0.0006$ $\mathrm{EI}(\mathrm{kJ} /$ day $)+9.94, \mathrm{r}=0.36, \mathrm{p}<0.01 ;$ TDC $(\mathrm{n}=16)$ : FFMI $\left(\mathrm{kg} / \mathrm{m}^{2}\right)=0.0005 \mathrm{EI}(\mathrm{kJ} /$ day $)+9.96, \mathrm{r}=0.57, \mathrm{p}<0.05$.

groups, as energy intake increased, FFMI increased proportionately at the same rate. The relationship between energy intake and FFMI was not significant when considering the gross motor functional abilities of the children with CP. There were no other significant correlations be- 
tween any body composition and dietary intake variables in the children with CP (even when considering functional ability or feeding method) or the TDC. Relationships investigated (and associated range of $\mathrm{r}$ values) included energy intake and body fat (in \%; $r=-0.02$ to 0.21 ), protein intake (\%) and FFMI ( $\mathrm{r}=-0.43$ to 0.10 ), protein intake (in $\%$ ) and body fat (in \%; $r=-0.13$ to 0.29 ), as well as fat intake (in \%) and body fat (in \%; $r=-0.24$ to 0.15 ).

\section{Discussion}

The aim of this study was to determine the relationships between energy intake, macronutrient intake and body composition in preschool-aged children with $\mathrm{CP}$ according to gross motor functional ability and in comparison to TDC. These variables were measured using validated methods rather than extrapolated from proxy measures. The only significant established relationship in both the children with CP and the TDC was that between energy intake and FFMI, which was stronger in the TDC. There was no difference in the slopes or intercepts of the relationships between both groups. We found no significant relationships between total energy or fat intakes and percentage body fat, or protein intake and FFMI in children with CP or TDC.

Children with CP are similar to TDC in that they are partitioning energy intake to increase FFM rather than store it as body fat, due to the relationship between energy intake and FFMI. This relationship, however, was weaker in the children with CP, most probably due to the ambulatory status. The children in the current study ranged from those who were ambulant to those who were not ambulant. Children who are unable to ambulate may not increase FFM due to weight-bearing activity (independent of their total energy intake), unlike children who are marginally ambulant or ambulant.

The absence of any relationships between other dietary and body composition variables is a significant finding and is consistent with published literature concerning TDC [40-45]. This suggests that the interactions between various dietary and body composition parameters in this young age group are not considerably different from a typically developing population, and can continue to be monitored and researched using the same theoretical principles.

The macronutrient composition of the diet was similar for all children in this study, regardless of differences in energy intake. Protein and fat intake, both as a factor of body weight and as a percentage of overall energy intake, were similar across all functional levels in children with $\mathrm{CP}$ and reflected values seen in TDC. There were no major imbalances in the proportion of macronutrients in any group of children. Differences only emerged when considering the feeding method. The tube-fed, non-ambulant children had significantly lower protein intakes compared to those who were orally fed. These children, however, were well above the national recommended daily intake of protein based on body weight (1.8 vs. $0.91-$ $1.08 \mathrm{~g} / \mathrm{kg} /$ day depending on age) [46]. This level of protein intake is consistent with data concerning protein intakes in Australian children, which detail protein intake (relative to overall energy intake) to be, on average, $16.6 \%$ for children aged $2-3$ years and $16.2 \%$ for children aged 4-8 years [47].

There was no indication of higher body fat percentages in those children who were tube fed, which has been reported as an adverse consequence of tube feeding in older, non-ambulant children with CP [10]. This result, however, could be due to the small sample size $(n=6)$ and further investigation is required.

Information regarding micronutrient status was not available for the current cohort, as a 3-day weighed food record is not a valid dietary assessment method to accurately assess micronutrient status in children with CP. A longer recording period coupled with blood analyses would be more appropriate [48-51]. To report the adequacy of micronutrient intake in this cohort of children would be inappropriate and misleading.

Lower FFMI in marginally ambulant and non-ambulant children compared to ambulant children and TDC were evident in the study population. At this point in time, these cross-sectional differences in body composition in preschool-aged children with CP cannot be entirely attributed to the nutrient composition of the diet. This is consistent with literature describing the links between dietary fat intake and excess adiposity and obesity in TDC. In 77 preschool-aged children (1.5-4.5 years), there was no significant relationship between fat intake and body fat percentage, despite the children being grouped into tertiles based on their percentage of dietary intake from fat [40].

Although it is evident that nutritional intervention has the potential to positively change body composition in children with CP [20], the ability to establish prospective links between dietary intake and body composition remains difficult. In adult populations, these links are evident, especially the relationship between fat intake and adiposity [52-55]. Conversely, results from well-designed, large cohort studies investigating these variables in chil- 
dren remain inconsistent and inconclusive [40-45, 56]. These relationships are difficult to elucidate in a crosssectional study, but findings suggest that they develop over time and are not yet evident in preschool-aged children with CP.

Aspects of daily energy expenditure, in particular a child's physical activity levels, may have a greater impact on body composition at this early age, due to the weightbearing exercises required to increase both muscle mass and bone density [57-60]. Energy expenditure and physical activity levels of children with CP decrease as their severity of gross motor impairment increases, due to movement restrictions and limitations. These levels have been shown to be significantly lower in children with $\mathrm{CP}$ compared to TDC $[11,12,18,61]$. Additionally, in a study of 32 children with CP aged between 2.9 and 4.4 years of all functional abilities, FFM and GMFCS level explained $67 \%$ of the variability in total energy expenditure [unpubl. data]. Future research should focus on investigation of total energy expenditure, in particular, physical activity levels in young children with CP using validated measures across the spectrum of gross motor functional abilities.

In conclusion, other than a relationship between energy intake and FFMI, which was stronger in the TDC when compared to the children with $\mathrm{CP}$, no other links between dietary intake and body composition variables were established in this study. Further research is required to examine the longitudinal effects of macronutrient intake on body composition parameters in a cohort of children with CP. Contributing factors, such as physical activity levels, should be concurrently investigated to determine the timing and impact of nutritional and body composition changes in this population, and the effect on growth, health and development. Detailed nutritional and physical activity educational strategies can then be developed and the optimal period in which to target nutritional interventions and rehabilitation can be determined.

\section{Acknowledgements}

We would like to thank all of the children and families who have participated in the study for their time and efforts. We would also like to thank Fiona Caristo, Lauren Forbes, Jo-Anne McMah, Laura Pareezer, Paula Beall, Christine Finn and Rachel Jordan for their help with recruitment and data collection, and Katherine Benfer for analyses of feeding videos.

Sources of support were an Australian Postgraduate Award Scholarship (J.L.W.), a University of Queensland School of Medicine Research Scholar Scholarship (J.L.W.), an NHMRC for Project Grant, 'Queensland Cerebral Palsy Child Study: Longitudinal Growth, Nutrition and Physical Activity in Children' (569605; P.S.W.D., R.N.B., K.L.B. and R.D.S.), an NHMRC for Project Grant, 'VicCPChild - Prospective Cohort Study of Children with Cerebral Palsy' (465128; R.N.B.), an NHMRC Career Development Fellowship (1037220; R.N.B.), a Smart State Fellowship from the Queensland Government (R.N.B.), the Royal Children's Hospital Foundation, Queensland (R.N.B. and P.S.W.D.) and the University of Queensland Foundation (R.N.B.).

\section{Disclosure Statement}

All authors have no conflicts of interest to disclose. Funding sources are stipends for researchers or program grants only. Funding bodies were not involved in the study design, data collection, data analysis, paper preparation and/or publication decisions.

\section{References}

1 Brooks J, Day S, Shavelle R, Strauss D: Low weight, morbidity and mortality in children with cerebral palsy: new clinical growth charts. Pediatrics 2011;128:e299-e307.

2 Day SM, Strauss DJ, Vachon PJ, Rosenbloom L, Shavelle RM, Wu YW: Growth patterns in a population of children and adolescents with cerebral palsy. Dev Med Child Neurol 2007;49:167-171.

- 3 Stevenson RD, Conaway M, Chumlea W, Rosenbaum P, Fung E, Henderson RC, Worley G, Liptak G, O'Donnell M, Samson-Fang $\mathrm{L}$, et al: Growth and health in children with moderate-to-severe cerebral palsy. Pediatrics 2006;118:1010-1018.
4 Stallings VA, Charney EB, Davies JC, Cronk CE: Nutritional status and growth of children with diplegic or hemiplegic cerebral palsy. Dev Med Child Neurol 1993;35:9971006.

5 Stallings VA, Charney EB, Davies JC, Cronk CE: Nutrition-related growth failure of children with quadriplegic cerebral palsy. Dev Med Child Neurol 1993;35:126-138.

6 Stallings VA, Cronk CE, Zemel BS, Charney EB: Body composition in children with spastic quadriplegic cerebral palsy. J Pediatr 1995; 126:833-839.
7 Stevenson RD, Hayes RP, Cater LV, Blackman JA: Clinical correlates of linear growth in children with cerebral palsy. Dev Med Child Neurol 1994;36:135-142.

8 Kuperminc MN, Stevenson RD: Growth and nutrition disorders in children with cerebral palsy. Dev Disabil Res Rev 2008;14:137-146.

$\checkmark 9$ Benigni I, Devos P, Rofidal T, Seguy D: The CP-MST, a malnutrition screening tool for institutionalized adult cerebral palsy patients. Clin Nutr 2011;30:769-773.

10 Sullivan PB, Alder N, Bachlet AM, Grant H, Juszczak E, Henry J, Vernon-Roberts A, Warner J, Wells J: Gastrostomy feeding in cerebral palsy: too much of a good thing? Dev Med Child Neurol 2006;48:877-882. 
-11 Bandini LG, Schoeller DA, Fukagawa NK, Wykes LJ, Dietz WH: Body composition and energy expenditure in adolescents with cerebral palsy or myelodysplasia. Pediatr Res 1991;29:70-77.

-12 van den Berg-Emons HJG, Saris WHM, de Barbanson DC, Westerterp KR, Huson A, van Baak MA: Daily physical activity of schoolchildren with spastic diplegia and of healthy control subjects. J Pediatr 1995;127: 578-584.

-13 van den Berg-Emons RJG, van Baak MA, Westerterp KR: Are skinfold measurements suitable to compare body fat between children with spastic cerebral palsy and healthy controls? Dev Med Child Neurol 1998;40: 335-339.

14 Kuperminc MN, Gurka MJ, Bennis JA, Busby MG, Grossberg R, Henderson RC, Stevenson RD: Anthropometric measures: poor predictors of body fat in children with moderate to severe cerebral palsy. Dev Med Child Neurol 2010;52:824-830.

15 Arrowsmith FE, Allen J, Gaskin K, Somerville $\mathrm{H}$, Clarke S, O'Loughlin E: The effect of gastrostomy tube feeding on body protein and bone mineralization in children with quadriplegic cerebral palsy. Dev Med Child Neurol 2010;52:1043-1047.

-16 Arrowsmith FE, Allen JR, Gaskin KJ, Somerville $\mathrm{H}$, Birdsall J, Barzi F, O'Loughlin EV: Nutritional rehabilitation increases the resting energy expenditure of malnourished children with severe cerebral palsy. Dev Med Child Neurol 2012;54:170-175.

17 Öztürk M, Kutluhan S, Demirci S, Akhan G, Kisioglu AN, Akgun S, Haciahmetoglu H: Dietary assessment of children with cerebral palsy: case control study in Isparta. Eastern J Med 2004;9:22-25.

-18 Stallings VA, Zemel BS, Davies JC, Cronk $\mathrm{CE}$, Charney EB: Energy expenditure of children and adolescents with severe disabilities: a cerebral palsy model. Am J Clin Nutr 1996; 64:627-634.

19 Sullivan PB, Juszczak E, Bachlet AM, Lambert B, Vernon-Roberts A, Grant HW, Eltumi M, McLean L, Alder N, Thomas AG: Gastrostomy tube feeding in children with cerebral palsy: a prospective, longitudinal study. Dev Med Child Neurol 2005;47:77-85.

20 Vernon-Roberts A, Wells JCK, Grant H, Alder N, Vadamalayan B, Eltumi M, Sullivan PB: Gastrostomy feeding in cerebral palsy: enough and no more. Dev Med Child Neurol 2010;52:1099-1105

- 21 Badawi N, Watson L, Petterson B, Blair E, Slee J, Haan E, Stanley F: What constitutes cerebral palsy? Dev Med Child Neurol 1998; 40:520-527.

22 Davies PSW, Coward WA, Gregory J, White A, Mills A: Total energy expenditure and energy intake in the pre-school child: a comparison. Br J Nutr 1994;72:13-20.
23 Bell KL, Boyd RN, Tweedy SM, Weir KA, Stevenson RD, Davies PSW: A prospective, longitudinal study of growth, nutrition and sedentary behaviour in young children with cerebral palsy. BMC Public Health 2010;10:179.

24 Nielsen SB, Montgomery C, Kelly LA, Jackson DM, Reilly JJ: Energy intake variability in free-living young children. Arch Dis Child 2008;93:971-973.

25 Davies PSW, Cole TJ: The adjustment of measures of energy expenditure for body weight and body composition. Int J Body Compos Res 2003;1:45-50.

26 Halliday D, Miller AG: Precise measurement of total body water using trace quantities of deuterium oxide. Biomed Mass Spectrom 1977;4:82-87.

27 Speakman JR: Doubly Labelled Water: Theory and Practice. London, Chapman \& Hall, 1997.

28 Speakman JR, Nair KS, Goran MI: Revised equations for calculating $\mathrm{CO}_{2}$ production from doubly labeled water in humans. Am J Physiol 1993;264:E912-E917.

29 Schoeller DA, van Santen E: Measurement of energy expenditure in humans by doubly labelled water. J Appl Physiol 1982;53:955-959.

30 Fomon SI, Haschke F, Ziegler EE, Nelson SE: Body composition of reference children from birth to age 10 years. Am J Clin Nutr 1982;35: 1169-1175.

-31 VanItallie TB, Yang M, Heymsfield SB, Funk RC, Boileau RA: Height-normalized indices of the body's fat-free mass and fat mass: potentially useful indicators of nutritional status. Am J Clin Nutr 1990;52:953-959.

32 Wells JCK, Fewtrell MS: Measuring body composition. Arch Dis Child 2006;91:612617.

33 Palisano R, Rosenbaum P, Walter S, Russell D, Wood E, Galuppi B: Development and reliability of a system to classify gross motor function in children with cerebral palsy. Dev Med Child Neurol 1997;39:214-223.

34 Palisano RJ, Rosenbaum P, Bartlett D, Livingston MH: Content validity of the expanded and revised Gross Motor Function Classification System. Dev Med Child Neurol 2008;50:744-750.

35 Sheppard JJ: Dysphagia Disorders Survey and Dysphagia Management Staging Scale (Adult and Paediatric Applications): User's Manual, Australian ed. Brisbane, Centre for Developmental Disabilities, 2002.

-36 Calis EAC, Veugelers R, Sheppard JJ, Tibboel D, Evenhuis HM, Penning C: Dysphagia in children with severe generalized cerebral palsy and intellectual disability. Dev Med Child Neurol 2008;50:625-630.

37 Manios Y, Grammatikaki E, Papoutsou S, Liarigkovinos T, Kondaki K, Moschonis G: Nutrient intakes of toddlers and preschoolers in Greece: the GENESIS study. J Am Diet Assoc 2008; 108:357-361.
38 Centers for Disease Control and Prevention: Clinical Growth Charts (version current August 4, 2009). http://www.cdc.gov/ growthcharts/clinical_charts.htm (accessed March 16, 2010).

39 Cole TJ: The LMS method for constructing normalized growth standards. Eur J Clin Nutr 1990;44:45-60.

40 Atkin LM, Davies PS: Diet composition and body composition in preschool children. Am J Clin Nutr 2000;72:15-21.

-41 Magary MA, Daniels LA, Boulton TJC, Cockington RA: Does fat intake predict adiposity in healthy children and adolescents aged 2-15 years? A longitudinal analysis. Eur J Clin Nutr 2001;55:471-481.

42 Rodriguez G, Moreno LA: Is dietary intake able to explain differences in body fatness in children and adolescents? Nutr Metab Cardiovasc Dis 2006;16:294-301.

43 Moreno LA, Rodriguez G: Dietary risk factors for the development of childhood obesity. Curr Opin Clin Nutr Metab Care 2007; 10:336-341.

44 Davies PSW: Diet composition and body mass index in pre-school children. Eur J Clin Nutr 1997;51:443-448.

45 Ricketts CD: Fat preferences, dietary fat intake and body composition in children. Eur J Clin Nutr 1997;51:778-781.

46 National Health and Medical Research Council: Nutrient Reference Values for Australia and New Zealand Including Recommended Dietary Intakes. Woden, Department of Health and Ageing, 2005.

47 Commonwealth Scientific Industrial $\mathrm{Re}$ search Organisation (CSIRO) Preventative Health National Research Flagship and University of South Australia: 2007 Australian National Children's Nutrition and Physical Activity Survey - Main Findings. Barton, 2008.

48 Livingstone MBE, Robson PJ, Wallace JMW: Issues in dietary intake assessment of children and adolescents. Br J Nutr 2004; 92:S213-S222.

49 Hillesund E, Skranes J, Trygg KU, Bohmer T: Micronutrient status in children with cerebral palsy. Acta Paediatr 2007;96:1195-1198.

50 Schoendorfer N, Boyd R, Davies PSW: Micronutrient adequacy and morbidity: paucity of information in children with cerebral palsy. Nutr Rev 2010;68:739-748.

51 Schoendorfer NC, Vitetta L, Sharp N, DiGeronimo $\mathrm{M}$, Wilson $\mathrm{G}$, Coombes JS, Boyd $\mathrm{R}$, Davies PSW: Micronutrient, antioxidant, and oxidative stress status in children with severe cerebral palsy. JPEN J Parenter Enteral Nutr 2012, DOI: 10.1177/0148607112447200.

52 Doucet E, Almeras N, White MD, Despres J-P, Bouchard C, Tremblay A: Dietary fat composition and human adiposity. Eur J Clin Nutr 1998;52:2-6. 
53 Miller WC, Lindeman AK, Wallace J, Niederpruem M: Diet composition, energy intake and exercise in relation to body fat in men and women. Am J Clin Nutr 1990;47: 995-1000.

54 Nelson LH, Tucker LA: Diet composition related to body fat in a multivariate study of 203 men. J Am Diet Assoc 1996;96:171-177.

55 Tucker LA, Kano MJ: Dietary fat and body fat: a multivariate study of 205 adult females. Am J Clin Nutr 1992;56:616-622.

56 Tucker LA, Seljaas GT, Hager RL: Body fat percentage of children varies according to their diet composition. J Am Diet Assoc 1997;97:981-986.
57 Henderson RC, Lin PP, Greene WB: Bonemineral density in children and adolescents who have spastic cerebral palsy. J Bone Joint Surg Am 1995;77:1671-1681.

58 Stevenson RD, Conaway MR, Barrington JW, Cuthill SL, Worley G, Henderson RC: Fracture rate in children with cerebral palsy. Pediatr Rehabil 2006;9:396-403.

59 Henderson RC, Lark RK, Gurka MJ, Worley G, Fung EB, Conaway M, Stallings VA, Stevenson RD: Bone density and metabolism in children and adolescents with moderate to severe cerebral palsy. Pediatrics 2002;110:e5.
60 Henderson RC, Kairalla J, Abbas A, Stevenson RD: Predicting low bone density in children and young adults with quadriplegic cerebral palsy. Dev Med Child Neurol 2004;46: 416-419.

61 Bell KL, Davies PSW: Energy expenditure and physical activity of ambulatory children with cerebral palsy and of typically developing children. Am J Clin Nutr 2010;92:313319.

62 Walker JL, Bell KL, Boyd RN, Davies PSW: Validation of a three-day weighed food record for measuring energy intake in preschool-aged children with cerebral palsy. Clin Nutr 2012; Epub ahead of print. 